\title{
Exergy Modelling of an Organic Rankine Cycle Energized by Heat from Parabolic Trough Collector with Thermal Storage
}

\author{
Ratha Z. Mathkor, Brian Agnew, Mohammed A. Al-Weshahi, and Nuri Eshoul
}

\begin{abstract}
A thermal assessment study of an Organic Rankine Cycle (ORC) energized by heat absorbed from a parabolic trough collectors (PTC) is presented in this paper. The IPSEpro software is used to model the system of ORC and PTC with thermal storage located in Derna, Libya. The system is examined using three modes of operation. They are low-solar radiation mode, high-solar radiation mode, and storage mode. The solar radiation is classified into low and high solar radiation according to times of the system operation during the day. Part of the absorbed solar energy by the collectors used to produce the power and the remaining energy is used to charge the thermal storage to operate the system during the storage mode in the night. The simulation results are used to assess the system performance using energy and exergy analysis. The study showed that PTC collector was the main contributor of the energy and exergy losses within the PTC system and the evaporator within in the ORC. At this specific weather conditions, the ORC was able to produce about 1.5 MW electrical power from the powered PTC heat with thermal storage during the day and night. Moreover, exergy efficiency of the overall system was $8.94 \%, 5.38 \%$ and $5.47 \%$ for low-solar radiation, high-solar radiation and storage mode respectively.
\end{abstract}

Index Terms-Energy and exergy analysis, ORC, PTC, thermal storage.

\section{INTRODUCTION}

In recent years, much environmental degradation has happened due to the increase in fossil fuel consumptions. Therefore research focused on new energy conversion technologies that could be greener and sustainable. These technologies used new energy sources such as wind energy, solar energy, waste heat and geothermal energy as low temperature heat sources. The ORC is a promising technology for converting low grade heat to electrical energy. The ORC powered by the solar energy was found to be an attractive option because it offers relatively good thermal efficiency at low temperatures and these combinations make it attractive option on some remote areas. In addition, it is considered an environmentally friendly choice since it utilizes solar energy. Many studies have been carried out to investigate and study performance enhancement of these

Manuscript received October 30, 2014; revised April 29, 2015.

Brian Agnew, Ratha Z. Mathkor, and Nuri Eshoul are with the School of Mechanical and Systems Engineering, Newcastle University, Newcastle Upon Tyne, UK (e-mail: brian.agnew@ncl.ac.uk, r.z.h.mathkor1@ncl.ac.uk and n.m.m.eshoul1@ncl.ac.uk).

Mohammed A. Al-Weshahi is with the Engineering Department, Shinas College of Technology, Alaqr, Oman (e-mail: mohammed.alwashahi@shct.edu.om). technologies

Nafey et al. [1] performed a comparisons of an ORC energized by thermal energy absorbed by a parabolic trough collector, a flat plate collector and a compound parabolic concentrator using MatLab/SimuLink code. The generated electrical power from the ORC was supplied to operate Reverse Osmosis (RO) desalination; the results showed that the parabolic trough collector, flat plate collector and compound parabolic concentrator are considered effective with toluene, butane and hexane respectively. The study revealed that increasing the evaporation temperature of the collector will result in a decrease of the collector area, working fluid flow rate, condenser area and condenser heat load and increase of the turbine power, ORC efficiency, pump work, specific power consumption, and reverse osmosis operating pressure. The PTC system was to be found the most suitable choice among these systems. The properties for twenty fluids working with solar ORC plant were investigated thermodynamically and environmentally by Tchanche et al. [2]. This plant was tested in a hot area with ambient temperature of $28^{\circ} \mathrm{C}$. In the study the solar collector provided the plant with hot water at $90{ }^{\circ} \mathrm{C}$ with air cooled condenser. The results revealed that $\mathrm{R} 134 \mathrm{a}$ was the most suitable for solar organic Rankine cycles. R152a, R600a, R600, and R290 are suitable too thermodynamically but not environmentally due to their flammability.

Al-Sulaiman et al. [3] presented an exergy analysis of a steam Rankine cycle combined with ORC. The cycles were driven by parabolic trough solar collectors and various working was investigated for the ORC. The results showed that the solar irradiation increases the exergetic efficiency. Moreover, the highest exergetic efficiency was $26 \%$ for combined cycle and the greatest performance was with $\mathrm{R} 134 \mathrm{a}$ as working fluid followed by R152a with $25 \%$ exergetic efficiency and the worst value for exergetic efficiency was $20 \%$ with R600a. The solar collector was the main source for exergy destruction with $70 \%$ of the whole destroyed exergy. $19 \%$ of the destroyed exergy was in the evaporator. Quoilin et al. [4] evaluated the performance of the organic Rankine cycle with solar energy. The cycle used parabolic though collectors to gather the energy from the sun and storage tanks to mitigate the solar irradiation and to keep constant operation of the ORC. Various working fluids were compared and two types of expansion machine were simulated. It was observed that the steady state electrical efficiency was about $8 \%$ and the best fluid was R245fa.

Ling He et al. [5] used TRANSYS software to simulate the solar organic Rankine cycle with trough collector and tank thermal storage. The effect of various parameters was 
examined on the efficiency of parabolic trough collector. The results show that the increase in the interlayer pressure will cause an increase in the heat loss of the solar collector until a specific value then will stay constant at this value the change of flow rate of high temperature oil with the heat collecting efficiency will change similar to the change of heat loss of the solar collector with the interlayer pressure. The results showed that the best volume for thermal storage was respectively $100,150,50$, and $0 \mathrm{~m}^{3}$ for spring equinox, summer solstice, autumnal equinox and winter solstice respectively. The literature review showed that the low grade technologies are unfeasible because of their low effectiveness and high cost. Compare to the conventional plants, it is struggling to be the best source of energy Therefore, these technologies need further research to become more efficient, commercially productive and economically competitive. Most of the researches in the literature review used software such as TRANSYS, Thermolib/Simulink and IPSEpro to simulate the solar collector with low grade technologies. Comparing these modelling programs was achieved and IPSEpro software was chosen to use in this work because it provides the flexibility user-generated subroutines has data for most of the commercial organic fluids and the high temperature oils available in this software. In addition, the available version (6.0) of IPSEpro is state of art.

Therefore this study has four aims: firstly to model the ORC with Toluene working fluid energized by heat from the PTC at a Mediterranean area climate such as Libya using IPSEpro software. Secondly to gain confidence on PTC modeling by validating the software output against experimentally results. Thirdly to use the simulation results of both systems with thermal storage to carry out energy and exergy analysis. Finally to evaluate the exergy destruction results in three modes as low-solar radiation mode, high-solar radiation mode, and storage mode.

\section{SYSTEM DESCRIPTION}

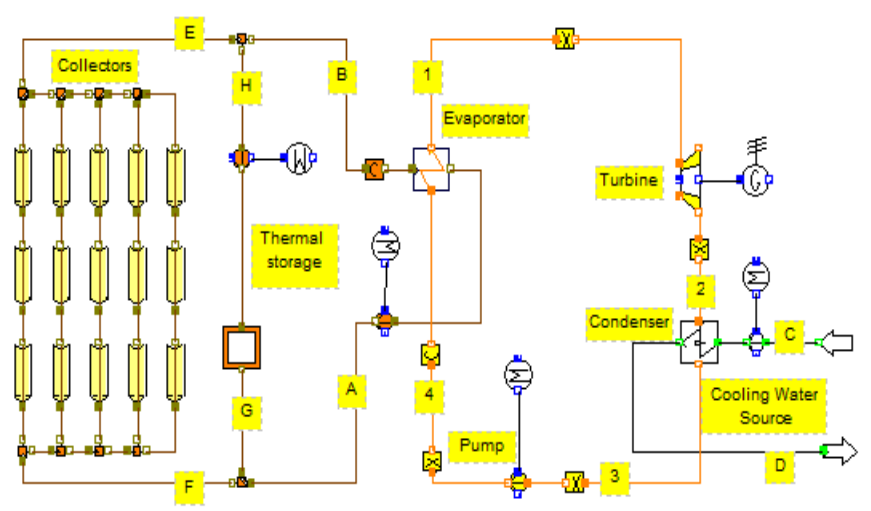

Fig. 1. The solar thermal power system.

The integration of a parabolic trough collector with ORC was modeled. The Fig. 1 shows the IPSEpro model of the ORC energized by PTC with thermal storage system. The ORC consists of an evaporator, a turbine, a condenser, and pump. The PTC model contains 148 collectors connected to the thermal storage and the heat transfer oil (HTO) in the absorber tube is Therminol VP-1. Thermal storage system is considered one main advantage of concentrating solar power technology over other technologies such as photovoltaic. The thermocline molten salt/filler storage [6] is used as thermal storage in this model. The local climatic conditions found in Derna (Libya) were taken into account. In Libya there are about 3200 hour per year of the average hours of solar brightness and $6 \mathrm{kWh}$ per square meter per day of the average solar radiation. Therefore, this can be a good reason for encouraging solar energy projects in Libya [7]. The performance of the model was investigated using energy and exergy analyses using real weather data obtained from local weather stations. The investigation was done using various models and libraries of the software package IPSEpro.

\section{VALIDATION}

The validation of the PTC model against experimental results carried out to make sure the correctness and reliability of the developed model. Fig. 2 present the comparisons between the PTC developed model and PTC experimental results [8] for heat loss. To assess the model confidence level for the collector, the calculation of relative difference between measured $\left(X_{i}\right)$ and model $\left(Y_{i}\right)$ data combined was achieved. The below expression [9] is applied to evaluate the correlation coefficient $(r)$ and root mean square percent deviation (e):

$$
\begin{gathered}
r=\frac{\left(N \sum X_{i} Y_{i}\right)-\left(\sum X_{i}\right)\left(\sum Y_{i}\right)}{\sqrt{\left(N \sum X_{i}^{2}\right)-\left(\sum X_{i}\right)^{2}} \sqrt{\left(\sum Y_{i}^{2}\right)-\left(\sum Y_{i}\right)^{2}}} \\
e=\sqrt{\frac{\sum\left(e_{i}\right)^{2}}{N}}
\end{gathered}
$$

where $e_{i}=\left[\frac{X_{i}-Y_{i}}{X_{i}}\right] \times 100$

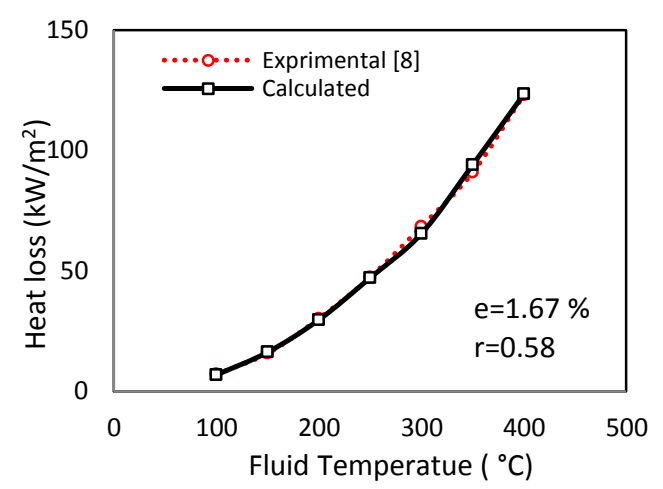

Fig. 2. Validation of the PTC model.

The equation (1) and (2) are used to evaluate the correlation coefficient $(r)$ and root mean square percent deviations (e) as shown in the same figure. It is observed that the PTC model has a good agreement with experimental results which helps in further thermal analysis.

\section{THERMAL ANALYSIS}

Based on the model design condition with ambient 
temperature of $25^{\circ} \mathrm{C}$ the thermal analysis was carried out. The analysis was carried out for Derna for highest direct normal irradiance $810 \mathrm{~W} / \mathrm{m}^{2}$ on $21^{\text {st }} \mathrm{July}$ at $12: 00$ and for lowest direct normal irradiance $487 \mathrm{~W} / \mathrm{m}^{2}$ [10]. The daily sunshine hours during July in Libya are about 12 hours. Solar modes during the day and storage mode during the night are considered as operation modes. The mode during the day is working for low and high solar radiation. The low solar radiation is the mode to collect the solar energy through specific times after the sunrise and before the sunset. The operation time for this mode during the day is stated (6:00 am to $8: 00$ am and 4:00 pm to $6: 00 \mathrm{pm}$ ). For the remaining time of the day the solar energy is the maximum during the day this mode which operates during 8:00 am to 4:00 pm is the high solar radiation mode. All this energy divided twice to operate the system and to charge the thermal storage. The system operated during the night using the stored energy in the thermal storage. Assuming 19.7\% of the energy is lost in the thermal storage due to the loss [6] and the remaining stored energy is operated the system during the night almost between 6:00 pm to 6:00 am. The solar field considered in this model comprised of 148 collectors which are single axis tracking and aligned on a north-south line. The aperture $\left(W_{0}\right)$ $=5 \mathrm{~m}$ and the length $(L)=49 \mathrm{~m}$ were the various design parameters for each collector. The PTC model contains collectors from types of LS-2 and with optical efficiency of 0.76 [11]. The fluid enters the collector with a temperature of $298^{\circ} \mathrm{C}$ and a mass flow rate of $218 \mathrm{~kg} / \mathrm{s}$ [12]. The outlet collector fluid temperature is found to be $341.2^{\circ} \mathrm{C}, 324.2^{\circ} \mathrm{C}$ and $330^{\circ} \mathrm{C}$ during high-solar radiation mode, low-solar radiation mode, and storage mod respectively. Total solar radiation incident on the collector subsystem is $29.4 \mathrm{MW}$ and 17.7 MW for low and high solar radiation modes respectively. The total energy absorbed by the absorbers is $22 \mathrm{MW}$ and 13.4 MW for low and high solar radiation modes respectively.

\section{A. Energy Analysis}

\section{1) Collector subsystem}

The efficiency of the collector and the thermal heat loss can be calculated from these equations:

$$
\begin{gathered}
\eta_{\text {collector }}=C_{0}+C_{1} \times \frac{T_{f}-T_{a}}{I_{\text {solar }}}-C_{2} \times \frac{\left(T_{f}-T_{a}\right)^{2}}{I_{\text {solar }}} \\
Q_{\text {loss }}=B_{1} \times \frac{T_{f}-T_{a}}{I_{\text {solar }}}+B_{2} \times \frac{\left(T_{f}-T_{a}\right)^{2}}{I_{\text {solar }}}
\end{gathered}
$$

where, $C_{0}, C_{1}, C_{2}, B_{1}, B_{2}$ are constants (73.1, 0.0011, $0.000047,-0.011$, and 0.00075 ) [8].

Energy received by the collector subsystem is

$$
Q_{i}=I \times N \times A
$$

where, $A=W_{0} \times L$

Energy absorbed by the collector absorber [5] is

$$
Q_{s}=Q_{i} \times \eta_{0}
$$

And the first low efficiency by the collector subsystem is

$$
\eta=Q_{s} / Q_{i}
$$

TABLE I: FLUIDS PROPERTIES FOR LOW-SOLAR RADIATION MODE

\begin{tabular}{ccccccc}
\hline \hline State & Fluid & $P($ bar $)$ & $\begin{array}{c}T \\
(\mathrm{C})\end{array}$ & $\begin{array}{c}m \\
(\mathrm{~kg} / \mathrm{sec})\end{array}$ & $\begin{array}{c}h \\
(\mathrm{kj} / \mathrm{kg})\end{array}$ & $\begin{array}{c}E x \\
(\mathrm{Kw})\end{array}$ \\
\hline 0 & Water & 1.01 & 298.2 & - & 104.93 & - \\
\hline 0 & Oil & 1.01 & 298.2 & - & 38.58 & - \\
0 & Toluene & 1.01 & 298.2 & - & -158.1 & - \\
1 & Toluene & 34.9 & 578.2 & 18.43 & 602.92 & 4890.95 \\
2 & Toluene & 1.11 & 453.4 & 18.43 & 472.45 & 2485.98 \\
3 & Toluene & 1.01 & 383.7 & 18.43 & 0.0500 & 365.710 \\
4 & Toluene & 35.0 & 385.7 & 18.43 & 6.2600 & 453.680 \\
$\mathrm{~A}$ & Oil & 14.0 & 597.3 & 178.0 & 630.70 & 36405.4 \\
$\mathrm{~B}$ & Oil & 13.9 & 571.0 & 178.0 & 568.91 & 28591.8 \\
$\mathrm{C}$ & Water & 1.20 & 298.1 & 208.3 & 104.95 & 6.48000 \\
$\mathrm{D}$ & Water & 1.10 & 308.1 & 208.3 & 146.74 & 147.640 \\
$\mathrm{E}$ & Oil & 15.0 & 571.1 & 218.0 & 569.10 & 35059.0 \\
$\mathrm{~F}$ & Oil & 14.0 & 597.3 & 218.0 & 630.69 & 44586.4 \\
$\mathrm{G}$ & Oil & 14.0 & 597.3 & 40.00 & 630.69 & 8180.99 \\
$\mathrm{H}$ & Oil & 16.0 & 571.1 & 40.00 & 569.10 & 6432.85 \\
\hline \hline
\end{tabular}

2) Receiver subsystem

Useful energy delivered to the fluid in the receiver is

$$
Q_{r}=N \times m_{f} \times C_{p f} \times\left(T_{f 0}-T_{f i}\right)
$$

$$
\text { Energy loss in receiver }=Q_{s}-Q_{r}
$$

$$
\text { Energy loss }(\%)=\left[\frac{Q_{s}-Q_{r}}{Q_{s}}\right] \times 100
$$

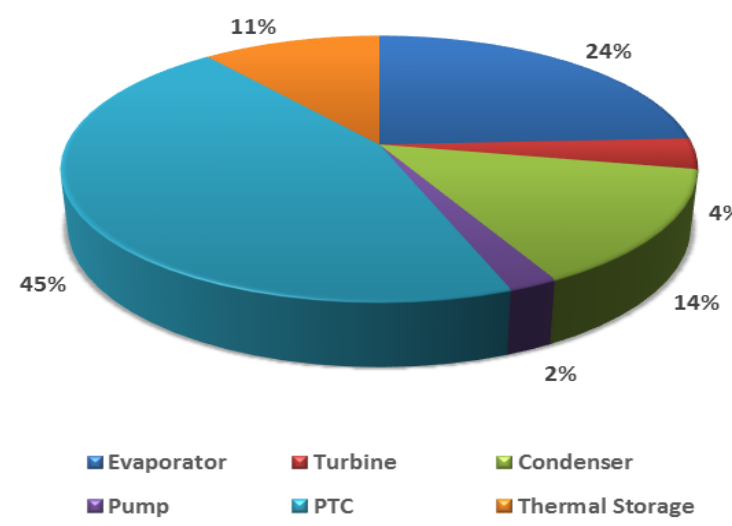

Fig. 3. Exergy destruction percentage for low-solar radiation mode.

First low efficiency for receiver subsystem is

$$
\eta=\frac{Q_{r}}{Q_{s}}
$$

Overall efficiency of the collector-receiver subsystem is

$$
\eta=\frac{Q_{r}}{Q_{i}}
$$

\section{3) ORC subsystem}

Net work done by the ORC is 


$$
W_{n e t}=W_{t}-W_{p}
$$

The energy analysis of the PTC subsystems showed that all components energy efficiency was above $20 \%$. Moreover, the collector receiver was the highest contributor of the energy losses and exergy losses among the subsystems.

\section{B. Exergy Analysis}

\section{1) Collector subsystem}

Exergy received by the collector subsystem is

$$
\dot{E} \dot{x}_{i}=Q_{i}\left[1-\left(\frac{T_{a}}{T_{s}}\right)\right]
$$

$T_{S}=6000 K^{\circ}$ absolute temperature of the Sun surface [13].

Exergy absorbed by the collector absorber

$$
E \dot{x}_{c}=Q_{s}\left[1-\left(\frac{T_{a}}{T_{r}}\right)\right]
$$

$$
\text { Exergy loss }=\text { irreversibility }(\mathrm{IR})=E \dot{x_{i}}-E \dot{x_{c}}
$$

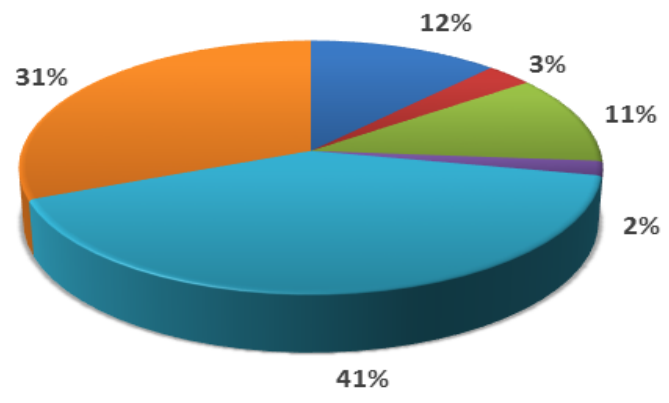

$$
\begin{array}{lll}
\square \text { Evaporator } & \square \text { Turbine } & \square \text { Condenser } \\
\square \text { Pump } & \square \text { PTC } & \square \text { Thermal Storage }
\end{array}
$$

Fig. 4. Exergy destruction percentage for high-solar radiation mode.

TABLE II: FluIDS PROPERTIES FOR HIGH-SOLAR RADIATION MODE

\begin{tabular}{ccccccc}
\hline \hline State & Fluid & $\begin{array}{c}P \\
(\mathrm{bar})\end{array}$ & $\begin{array}{c}T \\
(\mathrm{C})\end{array}$ & $\begin{array}{c}m \\
(\mathrm{~kg} / \mathrm{sec})\end{array}$ & $\begin{array}{c}h \\
(\mathrm{kj} / \mathrm{kg})\end{array}$ & $\begin{array}{c}E x \\
(\mathrm{Kw})\end{array}$ \\
\hline 0 & Water & 1.01 & 298.2 & - & 104.93 & - \\
\hline 0 & Oil & 1.01 & 298.2 & - & 38.58 & - \\
0 & Toluene & 1.01 & 298.2 & - & -158.1 & - \\
1 & Toluene & 34.9 & 578.2 & 18.74 & 602.92 & 4994.93 \\
2 & Toluene & 1.11 & 453.4 & 18.74 & 472.45 & 2549.93 \\
3 & Toluene & 1.01 & 383.7 & 18.74 & 0.0500 & 394.120 \\
4 & Toluene & 35.0 & 385.7 & 18.74 & 6.2600 & 483.680 \\
A & Oil & 14.0 & 614.3 & 109.0 & 671.50 & 24147.0 \\
B & Oil & 13.9 & 571.0 & 109.0 & 568.91 & 17514.5 \\
C & Water & 1.20 & 298.1 & 211.8 & 104.95 & 162.130 \\
D & Water & 1.10 & 308.1 & 211.8 & 146.74 & 305.140 \\
E & Oil & 15.0 & 571.1 & 218.0 & 569.11 & 35072.6 \\
F & Oil & 14.0 & 614.3 & 218.0 & 671.5 & 48294.1 \\
G & Oil & 16.0 & 614.4 & 109.0 & 671.87 & 24187.3 \\
H & Oil & 16.0 & 571.1 & 109.0 & 569.11 & 17536.3 \\
\hline \hline
\end{tabular}

$$
\text { Exergy loss }(\%)=\left(\frac{I R}{E \dot{x_{c}}}\right) \times 100
$$

Second law efficiency is

$$
\varepsilon=\frac{E \dot{x}_{c}}{E \dot{x}_{i}}
$$

2) Receiver subsystem

Exergy absorbed by the collector is

$$
\begin{aligned}
& E \dot{x}_{c}=Q_{s}\left[1-\left(\frac{T_{a}}{T_{s}}\right)\right] \\
& \% \text { exergy loss }=\left(\frac{I R}{E \dot{x_{c}}}\right) \times 100
\end{aligned}
$$

Useful exergy delivered is

$$
\dot{E} \dot{x}_{u}=N^{*} \dot{m}_{f}\left(\dot{E} \dot{x}_{o}-\dot{E} \dot{x}_{i}\right)=N^{*} \dot{m}_{f}\left[\left(h_{f o}-h_{f i}\right)-T_{a}\left(s_{f o}-s_{f i}\right)\right]
$$

Second law efficiency is

$$
\varepsilon=\frac{E \dot{x}_{u}}{E \dot{x}_{c}}
$$

The overall second law efficiency of the collector-receiver is

$$
\varepsilon=\frac{E \dot{x}_{u}}{E \dot{x}_{i}}
$$

\section{3) ORC subsystem}

The exergy for stream $(n)$ is

$$
E_{n}=\dot{m}_{n}\left[\left(h_{n}-h_{0}\right)-T_{0}\left(s_{n}-s_{0}\right)\right]
$$

where $m_{n}, s_{n}, h_{n}$ are stream mass flow rate ( $\left.\mathrm{kg} / \mathrm{s}\right)$, entropy $(\mathrm{kJ} / \mathrm{kg} \mathrm{K})$ and enthalpy $(\mathrm{kJ} / \mathrm{kg})$ respectively, $h_{o}, T_{o}, s_{o}$ are enthalpy, temperature, and entropy of the stream at the chosen zero datum for exergy values, selected at temperature $25{ }^{\circ} \mathrm{C}$, pressure $101.3 \mathrm{kPa}$. The evaluation of the exergy carries out with respect to the dead state (i.e. a reference environment).

From Fig. 1 can be seen that the only part of the hot oil heat at A utilize in the ORC evaporator, with the remainder at B returning back to the collector. The difference between those of the hot oil streams at A and B is the energy and exergy actually added to the ORC Fig. 1, so ORC exergy efficiency is defined as ORC net power $W_{\text {net }}$ divided by the exergy input to the evaporator $\left(\dot{\boldsymbol{E}}_{A}-\dot{\boldsymbol{E}}_{B}\right)$ : 


$$
\eta_{I I}=\frac{\dot{W}_{n e t}}{\left(\dot{E}_{A}-\dot{E}_{B}\right)}
$$

In the same way exergy efficiency for the overall system is defined as ORC net power divided by the exergy input to the collector:

$$
\eta_{I I}=\frac{\dot{W}_{n e t}}{E_{P T C . r e c}^{\bullet}}
$$

The exergy analysis revealed that second law efficiency of the collector was lower than first low efficiency. In Table ITable III, temperature, pressure, and mass flow rate data for oil, water, and Toluene are given according to their state numbers specified in Fig. 1. For each state listed in Table ITable III, exergy rates are also calculated. In addition, it was found that most of the exergy during the day was destroyed in the PTC system as shown in Fig. 3 and Fig. 4. Whereas the thermal storage has the most exergy destroyed during the night as shown in Fig. 5. The exergy destruction in the all ORC components was shown too. Moreover, it was found that 13.93 MW, 17.75 MW and 11.4 MW were the total exergy destruction in the overall system for low solar radiation mode, high solar radiation mode, and storage mode, respectively. It is necessary to mention that one of the higher exergy destruction within the ORC system is in the condenser which showed the possibilities of further cycle improvements by using rejected heat in condenser in other low temperature technologies such as absorption chiller or thermal desalination for cogeneration.

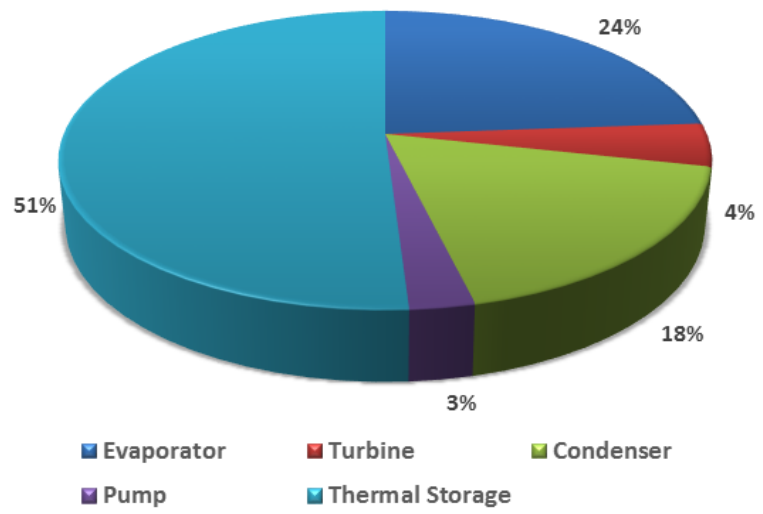

Fig. 5. Exergy destruction percentage for storage mode.

TABLE III: FLUIDS PROPERTIES FOR STORAGE MODE

\begin{tabular}{ccccccc}
\hline \hline State & Fluid & $\begin{array}{c}P \\
(\mathrm{~b})\end{array}$ & $\begin{array}{c}T \\
(\mathrm{C})\end{array}$ & $\begin{array}{c}m \\
(\mathrm{~kg} / \mathrm{sec})\end{array}$ & $\begin{array}{c}h \\
(\mathrm{kj} / \mathrm{kg})\end{array}$ & $\begin{array}{c}E x \\
(\mathrm{Kw})\end{array}$ \\
\hline 0 & Water & 1.01 & 298.1 & - & 104.9 & - \\
\hline 0 & Oil & 1.01 & 298.1 & - & 0.370 & - \\
0 & Toluene & 1.01 & 298.1 & - & -158.2 & - \\
1 & Toluene & 34.9 & 578.2 & 18.86 & 602.9 & 5026.44 \\
2 & Toluene & 1.11 & 453.4 & 18.86 & 472.4 & 2565.13 \\
3 & Toluene & 1.01 & 383.7 & 18.86 & 0.050 & 396.340 \\
4 & Toluene & 35.0 & 385.7 & 18.86 & 6.260 & 486.370 \\
A & Oil & 14.0 & 603.2 & 149.0 & 644.6 & 31207.0 \\
B & Oil & 13.9 & 571.1 & 149.0 & 569.0 & 23950.5 \\
C & Water & 1.20 & 298.1 & 213.2 & 104.9 & 162.410 \\
D & Water & 1.10 & 308.1 & 213.2 & 146.7 & 305.400 \\
G & Oil & 16.0 & 603.2 & 149.0 & 644.6 & 31207.1 \\
H & Oil & 16.0 & 571.3 & 149.0 & 569.4 & 24005.6 \\
\hline \hline
\end{tabular}

\section{CONCLUSION}

In this paper, modelling, validation and thermal assessment of a Parabolic Trough Collector (PTC) with thermal storage integrated with organic Rankine cycle (ORC) was carried out at Libya weather conditions. The PTC modelled using IPSEpro was validated against experimental data. The heat absorbed by the PTC was used to energize an Organic Rankine Cycle. The system was examined using three modes of operation, low-solar radiation mode, high-solar radiation mode and storage mode. The low-solar radiation and the high solar-radiation modes are during the day time and the storage mode is during the night time. The simulation results of the PTC and ORC models were used to perform energy and exergy analysis of both systems. The results revealed that in both energy and exergy analysis the collector receiver was the main contributor of the losses with $78.7 \%$ for energy losses and $88.5 \%$ for the exergy losses. The exergy efficiency of the overall system was $8.94 \%, 5.38 \%$ and $5.47 \%$ for low-solar radiation, high-solar radiation and storage mode respectively. At this specific study the solar ORC system was able to produce about 3.0 MW electrical power from the powered PTC heat and the thermal storage was able to store about half of this electrical power. So, the system is able to produce electrical power with a constant value of power during the day and night about 1.5 MW.

\begin{tabular}{ll} 
& \multicolumn{1}{c}{ NOMENCLATURE } \\
$A$ & Area \\
$C_{p}$ & Specific heat at constant pressure \\
$E x$ & Exergy \\
$h$ & Enthalpy \\
$I$ & Solar intensity \\
$I R$ & Irreiversibility \\
$H T O$ & Heat transfer oil \\
$L$ & Length \\
$m$ & Mass flow rate \\
$P$ & Pressure \\
$N$ & Number of collector \\
$O R C$ & Organic Rankine Cycle \\
$P T C$ & Prabolic Trough Collector \\
$Q$ & Heat transfer rate \\
$S$ & Entropy \\
$T$ & Temperature \\
$W_{o}$ & Aperture \\
$X_{i}$ & Theoretical values \\
$Y_{i}$ & Experimental values \\
& \\
Greek Symbols \\
$\eta$ & Thermal efficiency \\
$\varepsilon$ & Exergy efficiency \\
& \\
Subscripts & \\
$a$ & Ambient \\
$f$ & Fluid \\
$i$ & Inlet \\
$G$ & Generator \\
$L$ & Loss \\
$P$ & Outlet \\
& Pump \\
\hline & Absorber/solar \\
\hline &
\end{tabular}

\section{ACKNOWLEDGMENT}

I wish to acknowledge my supervisor Prof. Brian Agnew and my research partners Dr. Mohammed Al-Weshahi and Mr. Nuri Eshoul for their contributions during the writing of this paper and also for helping in proofreading the work. 


\section{REFERENCES}

[1] S. Nafey and M. A. Sharaf, "Combined solar organic Rankine cycle with reverse osmosis desalination process: Energy, exergy, and cost evaluations," Renewable Energy, vol. 35, no. 11, pp. 2571-2580, 2010.

[2] B. F. Tchanche et al., "Fluid selection for a low-temperature solar organic Rankine cycle," Applied Thermal Engineering, vol. 29, no. 1112, pp. 2468-2476, 2009.

[3] F. A. Al-Sulaiman, "Exergy analysis of parabolic trough solar collectors integrated with combined steam and organic Rankine cycles," Energy Conversion and Management, vol. 77, pp. 441-449, 2014.

[4] S. Quoilin et al., "Performance and design optimization of a low-cost solar organic Rankine cycle for remote power generation," Solar Energy, vol. 85, no. 5, pp. 955-966, 2011.

[5] Y. L. He et al., "Simulation of the parabolic trough solar energy generation system with organic Rankine cycle," Applied Energy, vol. 97, pp. 630-641, 2012.

[6] Z. Yang and S. V. Garimella, "Cyclic operation of molten-salt thermal energy storage in thermoclines for solar power plants," Applied Energy, vol. 103, pp. 256-265, 2013.

[7] A. M. A. Mohamed, A. Al-Habaibeh, and H. Abdo, "An investigation into the current utilisation and prospective of renewable energy resources and technologies in Libya," Renewable Energy, vol. 50, pp. 732-740, 2013.

[8] V. E. Dudley, G. J. Koip, M. Slon, and D. Kearney, Test Results SEGS LS-2 Solar Collector, Sandia National Laboratories, 1994.

[9] S. Dubey and G. N. Tiwari, "Thermal modeling of a combined system of photovoltaic thermal (PV/T) solar water heater," Solar Energy, vol. 82, no. 7, pp. 602-612, 2008.

[10] Y. Aldali and K. Morad, "Thermal performance improvement of Derna electric power station (unit5) using solar energy," Journal of Sustainable Development, vol. 7, pp. 60-71. 2014.

[11] H. Price et al., "Advances in parabolic trough solar power technology," Journal of Solar Energy Engineering, vol. 124, no. 2, pp. 109-125, 2002.

[12] A. Baghernejad and M. Yaghoubi, "Exergy analysis of an integrated solar combined cycle system," Renewable Energy, vol. 35, no. 10, pp. 2157-2164, 2010.

[13] R. Petela, "Exergy analysis of the solar cylindrical-parabolic cooker," Solar Energy, vol. 79, no. 3, pp. 221-233, 2005.

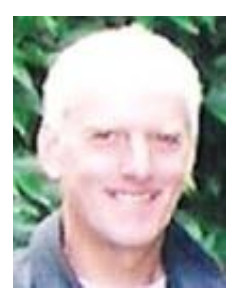

Brian Agnew is a professor in the School of Mechanical Engineering of Newcastle University, UK. He obtained the Ph.D. degree from the City University London, UK. His areas of research interests are renewable energy and energy conversion technology.

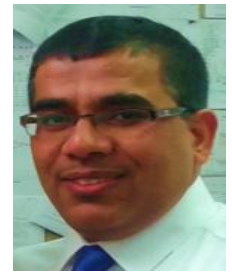

Mohammed A. Al-Weshahi obtained the Ph.D. degree from the Newcastle University, UK, in 2014 $\mathrm{He}$ was selected as a member of the staff in the Engineering Department, Shinas College of Technology, Alaqr, Oman. His areas of research interests are renewable energy and energy conversion technology.

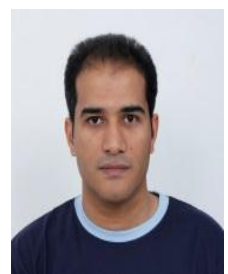

Ratha Mathkor is a Ph.D. student in the School of Mechanical Engineering, Newcastle University, UK. His advisor is Prof. Brian Agnew. He received his bachelor and master degrees in mechanical engineering from University of Benghazi, Libya. He is a permanent faculty member in Omer Al-Mukhtar University, Libya as a lecturer. His area of research interests is renewable energy.

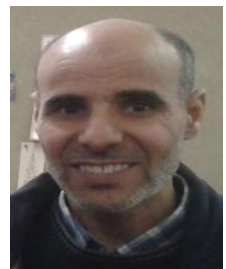

Nuri Eshoul is a Ph.D. student in the School of Mechanical Engineering, Newcastle University, UK His advisor is Prof. Brian Agnew. He received his bachelor degree in mechanical engineering from University of Tripoli, Libya and his master degree from Salford University, UK. His areas of research interests are energy conversion technology and renewable energy. 